\title{
The Effect of Shear Stress on Wax Deposit Thickness with and without Spiral Flow
}

Muhammad Ali Theyab*

Ministry of Higher Education and Scientific Research, Iraq

\begin{abstract}
The main objective of this research is to estimate and discuss the effect of shear stress on wax deposition in the hydrocarbon pipeline. Two sets of experimental data were used to analyse the effect of shear stress on wax deposition with and without spiral flow at different inlet coolant temperatures and different flow rates. A new mathematical model was developed during this study to estimate the shear stress, because of the spiral flow, on wax deposition. The concept of this model was based on the forces that influence on the crude oil flow in the pipe, with and without inserting the twisted plate to create spiral flow, depending on the pressure drop along the pipe. The results are presented that, increasing the shear stress, because of the effect of the spiral flow, leads to decrease the wax deposit thickness with increasing the pressure drop while the shear stress decreased in the case of crude oil flow without spiral flow leading to increasing the wax deposit thickness. On the other hand, increasing the inlet coolant temperature leads to decrease the shear stress and wax thickness because of decreasing the value of the crude oil viscosity. This developed model can be considered as a base model for similar studies to calculate the shear stress in the fluid flow pipelines using the twisted plate to create spiral flow.
\end{abstract}

Keywords: Wax deposit thickness; Shear stress; Spiral flow; Pressure drop

Nomenclature: F1=Inlet force $(\mathrm{N}) ; \mathrm{F} 2=$ Outlet force $(\mathrm{N}) ; \mathrm{F} 3=$ Shear stress force $(\mathrm{N}) ; \tau=$ Shear stress $(\mathrm{Pa}) ; P=$ Inlet pressure $(\mathrm{Pa}) ; \Delta P=$ Pressure drop along the pipe $(\mathrm{Pa}) ; A_{X}=$ The cross-section area of the pipe $\left(\mathrm{m}^{2}\right) ; r=$ The radius of the pipe $(\mathrm{m}) ; L=$ The length of the pipe $(\mathrm{m})$; $Q=$ The volumetric flow rate of the fluid $\left(\mathrm{m}^{3} / \mathrm{s}\right) ; \underline{U}=$ The fluid velocity $(\mathrm{m} / \mathrm{s}) ; A_{\text {Xpipe }}=$ The cross-section area of the pipe $\left(\mathrm{m}^{2}\right) ; A_{\text {Xplate }}=$ The crosssection area of the twisted plate $\left(\mathrm{m}^{2}\right)$

\section{Introduction}

There appears to be a trend to a reduction in wax deposition tendency on the pipe wall at the higher rates of shear, due to increase pipe wall shear stress. An increase in shear rate should encourage more wax particles to disperse towards the pipe wall; the corresponding increase in wall shear stress may cause the more loosely held deposits to be stripped from the pipe wall [1].

It is generally accepted that shear stress is mainly responsible for shearing away of wax molecules and crystals. The shear stress and Reynold's Number depend on the systems flow characteristics and they have a direct effect on the diffusion of wax molecules to the wall [2].

Dwivedi [3] showed that there is a general decreasing trend in the deposit thickness by increasing the shear stress and decreasing thermal driving force. Venkatesan [4] concluded that, at a fixed cooling rate, the gelation temperature decreases as the shear stress applied on the sample is increased. The gelation temperature is an appropriate measure of the onset of gelation under flowing conditions. This reduction in gelation temperature leads to a decrease in paraffin deposition because of the prevention of deposit formation instead of removal. This study, describes mathematically the steps to develop the shear stress correlation, because of the spiral flow, on wax deposition on the hydrocarbon pipe wall. Also, present the estimated shear stress inside the pipe, using the new correlation, and compare the values of shear stress with and without using the spiral flow.

\section{Methodology}

\section{Experimental data}

The experimental data of Theyab and Diaz [5,6], Tables 1 and 2

\begin{tabular}{|c|c|c|c|c|}
\hline Type of Flow & $\begin{array}{c}\text { Temperature } \\
\left({ }^{\circ} \mathrm{C}\right)\end{array}$ & $\begin{array}{l}\text { Pressure Drop } \\
(\mathrm{Pa})\end{array}$ & $\begin{array}{l}\text { Wax Thickness } \\
(\mathrm{mm})\end{array}$ & Resource \\
\hline Not Spiral & \multirow{2}{*}{14} & 1200 & 1.82 & [5] \\
\hline Spiral & & 4000 & 1.03 & [6] \\
\hline Not Spiral & \multirow{2}{*}{24} & 1000 & 1.5 & [5] \\
\hline Spiral & & 3400 & 0.85 & [6] \\
\hline Not Spiral & \multirow{2}{*}{33} & 900 & 0.7 & [5] \\
\hline Spiral & & 2500 & 0.36 & [6] \\
\hline Not Spiral & \multirow{2}{*}{40} & 600 & 0 & [5] \\
\hline Spiral & & 1700 & 0 & [6] \\
\hline
\end{tabular}

Table 1: The deposit wax thickness at different pressure drops, and different inlet coolant temperatures at flow rate $2.7 \mathrm{~L} / \mathrm{min}$ with and without the spiral flow $[5,6]$.

\begin{tabular}{|c|c|c|c|c|}
\hline $\begin{array}{l}\text { Type of } \\
\text { Flow }\end{array}$ & $\begin{array}{c}\text { Temperature } \\
\left({ }^{\circ} \mathrm{C}\right)\end{array}$ & $\begin{array}{l}\text { Pressure Drop } \\
(\mathrm{Pa})\end{array}$ & $\begin{array}{c}\text { Wax Thickness } \\
(\mathrm{mm})\end{array}$ & Resource \\
\hline Not Spiral & \multirow{2}{*}{14} & 3000 & 1.5 & [5] \\
\hline Spiral & & 8000 & 0.78 & [6] \\
\hline Not Spiral & \multirow{2}{*}{24} & 2700 & 1.36 & [5] \\
\hline Spiral & & 7000 & 0.61 & [6] \\
\hline Not Spiral & \multirow{2}{*}{33} & 2100 & 0.63 & [5] \\
\hline Spiral & & 6100 & 0.39 & [6] \\
\hline Not Spiral & \multirow{2}{*}{40} & 1200 & 0 & [5] \\
\hline Spiral & & 4500 & 0 & [6] \\
\hline
\end{tabular}

Table 2: The deposit wax thickness at different pressure drops, and different inlet coolant temperatures at flow rate $4.8 \mathrm{~L} / \mathrm{min}$ with and without the spiral flow $[5,6]$.

were used during this work to estimate the shear stress inside the crude oil pipeline, using the developed model, with and without spiral flow.

"Corresponding author: Muhammad Ali Theyab, Ministry of Higher Education and Scientific Research, Iraq, Tel: +447833846288; E-mail: theyabm@Isbu.ac.uk

Received January 27, 2018; Accepted March 26, 2018; Published March 31, 2018

Citation: Theyab MA (2018) The Effect of Shear Stress on Wax Deposit Thickness with and without Spiral Flow. J Pet Environ Biotechnol 9: 358. doi: 10.4172/21577463.1000358

Copyright: (c) 2018 Theyab MA. This is an open-access article distributed under the terms of the Creative Commons Attribution License, which permits unrestricted use, distribution, and reproduction in any medium, provided the original author and source are credited. 
They used a flow loop system to recirculate the waxy crude oil with API about 35 and the wax content about $20.15 \mathrm{wt} \%$, and to study the effect of the inlet coolant temperatures $14,24,33$ and $40^{\circ} \mathrm{C}$, the effect of the flow rates 2.7 and $4.8 \mathrm{~L} / \mathrm{min}$, and the effect of the spiral flow on wax deposit thickness.

\section{Derivation of shear stress model}

This section describes mathematically the steps to develop the shear stress model, because of the spiral flow, on wax deposition on the hydrocarbon pipe wall. It shows the forces that influence on the crude oil flow in the pipe with and without inserting the twisted plate depending on the pressure drop along the pipe.

\section{Fluid flow in a pipe}

The concept of the spiral flow mechanism in this research is based on an elemental fluid flowing in the pipe. The initial conditions for the elemental fluid are taken in the way that; the high-pressure value is taken from the injection side and drives uniformly decreasing throughout the pipe. Shearing action is integrated from the elemental radius up to maximum flow channel radius. The forces acting on the system are quantitatively described below $[7,8]$.

The driving force due to pressure (Force=pressure $\times$ area) can describe as shown in Figure 1 of this study.

\section{Where:}

Inlet force $=$ Inlet pressure $\times$ cross-section area of the pipe ( $\left.F_{1}=P A_{X}\right)$.

Outlet force $=$ outlet pressure $\times$ cross-section area of the pipe ( $\left.F_{2}=(P-\Delta P) A_{X}\right)$, Where, $P$ is the inlet pressure $(\mathrm{Pa}), A_{X}$ is the pressure drop along the pipe $(\mathrm{Pa})$, and $A_{X}$ is the cross-section area of the pipe $\left(\mathrm{m}^{2}\right)$.

Shear stress force $=$ shear stress $\times$ surface area of the pipe ( $F_{3}=\tau 2 \pi r L$ ).

Where, $\tau$ is the shear stress $(\mathrm{Pa}), r$ is the radius of the pipe $(0.00675 \mathrm{~m})$, and $L$ is the length of the pipe $(1.5 \mathrm{~m})$.

The driving force due to pressure equals to:

$$
F_{3}=F_{1}-F_{2}
$$

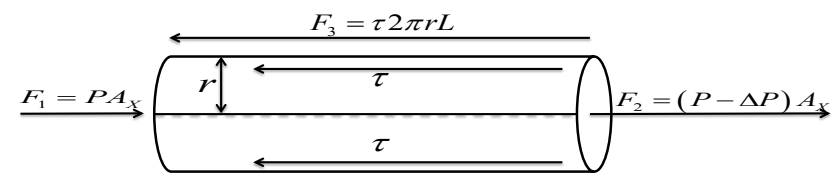

Figure 1: Forces affects on the element of fluid flow in a pipe.

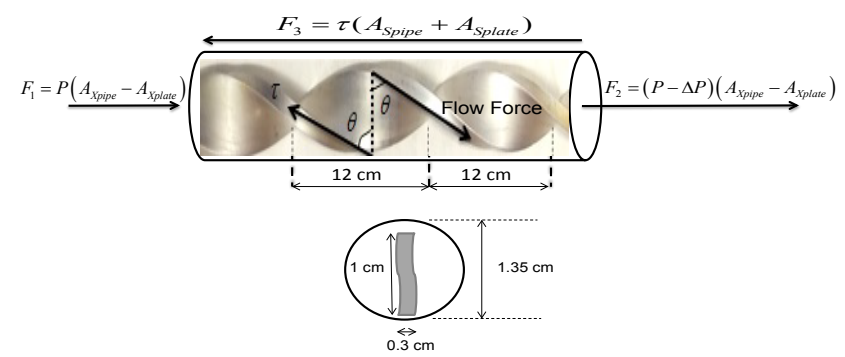

Figure 2: Forces affect on the element of fluid in a pipe with the effect of spiral flow created by inserting a twisted plate inside the pipe.

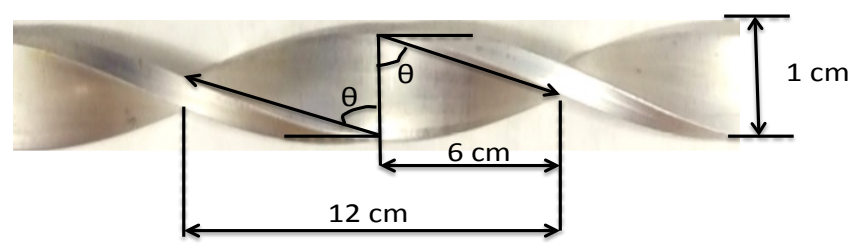

Figure 3: Estimate the angular flow of the twisted plate and equals to $\tan ^{-1}(6 / 0.5)=85^{\circ}$.

$\tau 2 \pi r L=P \pi r^{2}-(P-\Delta P) \pi r^{2}$, simplify the equation results to $\tau 2 \pi r L=\Delta P \pi r^{2}$, then shear stress equals to:

$$
\tau=\frac{\Delta P r}{2 L}
$$

The velocity of the fluid inside the pipe can be calculated from divide the volumetric flow rate to the cross-section area of the pipe $Q=u A$

$$
u=Q / \pi r^{2}
$$

Where, $Q$ is the volumetric flow rate of the fluid $\left(\mathrm{m}^{3} / \mathrm{s}\right), u$ is the fluid velocity $(\mathrm{m} / \mathrm{s})$.

\section{Fluid flow through spiral}

In order to develop an equation for the pipe wall shear stress plus the shear stress of the twisted plate inside the pipe, the following steps will illustrate that in Figure 2.

Inlet force $=$ inlet pressure $\times($ cross-section area of the pipe - cross section area of the twisted plate).

$$
F_{1}=P\left(A_{\text {Xpipe }}-A_{\text {Xplate }}\right)
$$

Where, $A_{\text {Xpipe }}$ is the cross-section area of the pipe $\left(\mathrm{m}^{2}\right)$, and $A_{\text {Xplate }}$ is the cross section area of the twisted plate $\left(\mathrm{m}^{2}\right)$.

$$
F_{1}=P\left(\pi r^{2}-3 \times 10^{-5}\right)
$$

Outlet force $=$ outlet pressure $\times$ (cross-section area of the pipe cross section area of the twisted plate).

$$
\begin{aligned}
& F_{2}=(P-\Delta P)\left(A_{\text {Xpipe }}-A_{\text {Xplate }}\right) \\
& F_{2}=(P-\Delta P)\left(\pi r^{2}-3 \times 10^{-5}\right) \\
& F_{2}=P \pi r^{2}-3 \times 10^{-5} P-\Delta P \pi r^{2}+3 \times 10^{-5} \Delta P
\end{aligned}
$$

In order, to calculate the shear stress force, it should be taken into account the shear stress of the pipe plus the shear stress results from the twisted plate inside the pipe.

The twisted plate divided to 12.5 sections; each section equal to 12 $\mathrm{cm}$ and height $1 \mathrm{~cm}$. Therefore, to calculate the total shear stress results from the twisted plate, it should be calculated the shear stress results from each section of the twisted plate multiplied by 12.5 . The surface area of each section of the twisted plate equals $3.12 \times 10^{-3} \mathrm{~m}^{2}$, and the angle of each section of the twisted plate estimates to be about $85^{\circ}$, (Figure 3), and it comes from $\tan ^{-1}(6 / 0.5)=85$.

Shear stress force $=($ shear stress $\times$ surface area of the pipe $)+($ shear stress $\times$ surface area of the twisted plate inside the pipe).

Shear stress force $=($ shear stress $\times$ surface area of the pipe $)+$ shear stress (number of twisted plate sections $\times \cos \theta \times$ surface area of the twisted plate section). 
Citation: Theyab MA (2018) The Effect of Shear Stress on Wax Deposit Thickness with and without Spiral Flow. J Pet Environ Biotechnol 9: 358. doi: 10.4172/2157-7463.1000358

$$
\begin{aligned}
& F_{3}=\tau 2 \pi r L+\tau\left(12.5 \times \cos \theta \times 3.12 \times 10^{-3}\right) \\
& F_{3}=\tau 2 \pi r L+\tau\left(12.5 \times \cos 85 \times 3.12 \times 10^{-3}\right) \\
& F_{3}=\tau 2 \pi r L+0.0034 \tau \\
& F_{3}=\tau(2 \pi r L+0.0034)
\end{aligned}
$$

In the case of the spiral flow, the driving force along the pipe due to pressure equals to:

$$
\begin{aligned}
& F_{3}=F_{1}-F_{2} \\
& \tau(2 \pi r L+0.0034)=P\left(\pi r^{2}-3 \times 10^{-5}\right)- \\
& \left(P \pi r^{2}-3 \times 10^{-5} P-\Delta P \pi r^{2}+3 \times 10^{-5} \Delta P\right)
\end{aligned}
$$

Simplify the equation,

$$
\begin{aligned}
& \tau(2 \pi r L+0.0034)=P \pi r^{2}-3 \times 10^{-5} P- \\
& P \pi r^{2}+3 \times 10^{-5} P+\Delta P \pi r^{2}-3 \times 10^{-5} \Delta P \\
& \tau(2 \pi r L+0.0034)=\Delta P \pi r^{2}-3 \times 10^{-5} \Delta P \\
& \tau(2 \pi r L+0.0034)=\Delta P\left(\pi r^{2}-3 \times 10^{-5}\right)
\end{aligned}
$$

So, the total shear stress results from the pipe and the twisted plate can be calculated from the following equation:

$$
\tau=\frac{\Delta P\left(\pi r^{2}-3 \times 10^{-5}\right)}{(2 \pi r L+0.0034)}
$$

The velocity can be calculated by dividing the volumetric flow rate to the (cross-section area of the pipe minus cross section area of the twisted plate).

$$
u=\frac{Q}{\left(\pi r^{2}-3 \times 10^{-5}\right)}
$$

\section{Results and Discussion}

In the case of fluid flow in a pipe without spiral, for example, at flow rate $2.7 \mathrm{~L} / \mathrm{min}$ and pressure drop $1200 \mathrm{~Pa}$, the shear stress calculated from equation (1) above equals to:

$$
\tau=\frac{(1200 \times 0.00675)}{(2 \times 1.5)}=2.7 \mathrm{~Pa} \text {, and by increasing the flow rate to } 4.8
$$

$\mathrm{L} / \mathrm{min}$, the shear stress at pressure drop $3000 \mathrm{~Pa}$ results using equation (1) to: $4.5 \times 10^{-5} \mathrm{~m}^{3} / \mathrm{s}$

Equation (1) represents the shear stress inside the pipe without the twisted plate.

For example at the fluid flow without spiral, to calculate the fluid velocity in the pipe at flow rate $2.7 \mathrm{~L} / \mathrm{min}\left(4.5 \times 10^{-5} \mathrm{~m}^{3} / \mathrm{s}\right)$ using equation (2) above results:

$$
u=4.5 \times 10^{-5} / \pi(0.00675)^{2}=0.31 \mathrm{~m} / \mathrm{s}
$$

By increasing the flow rate to $4.8 \mathrm{~L} / \mathrm{min}\left(8 \times 10^{-5} \mathrm{~m}^{3} / \mathrm{s}\right)$ lead to $u=8 \times 10^{-5} / \pi(0.00675)^{2}=0.56 \mathrm{~m} / \mathrm{s}$. The increase in the velocity means an increase in the shear stress that reduces wax deposit on the pipe wall.

In the case of fluid flow in a pipe with spiral, for example, at flow rate $2.7 \mathrm{~L} / \mathrm{min}$ and pressure drop $4000 \mathrm{~Pa}$, the shear stress calculated from equation (3) results:

$$
\tau=\frac{4000\left(\pi(0.00675)^{2}-3 \times 10^{-5}\right)}{(2 \pi \times 0.00675 \times 1.5+0.0034)}=6.75 P a, \text { and by increasing the flow }
$$

rate to $4.8 \mathrm{~L} / \mathrm{min}$., the shear stress at $8000 \mathrm{~Pa}$ results using equation (3) to: $\tau=13.51 \mathrm{~Pa}$

For example, to calculate the fluid velocity at flow rate $2.7 \mathrm{~L} / \mathrm{min}$ using equation (4) in the case of using the twisted plate inside the pipe leads to:

$u=\frac{4.5 \times 10^{-5}}{\left(\pi(0.00675)^{2}-3 \times 10^{-5}\right)}=0.4 \mathrm{~m} / \mathrm{s}$, and at flow rate $4.8 \mathrm{~L} / \mathrm{min}$. using the same equation leads to $u=0.71 \mathrm{~m} / \mathrm{s}$.

The velocity of the fluid flow is increased by inserting a twisted plate inside the pipe, because of reducing cross-section area of the pipe with the constant flow rate.

From the above, it can be concluded that the twisted plate changed the fluid flow type from laminar or turbulent to spiral flow depending on the velocity and the angle of the fluid flow. This angle analyses the angular flow to two forces one vertically to the wax deposit and the second force horizontally, those forces work together to reduce wax deposition on the pipe. Tables 3 and 4 show the data of shear stress at the different wax thickness, different pressure drop, and different inlet coolant temperatures.

At the same inlet coolant temperature, it can be seen that increasing the shear stress, because of the effect of the spiral flow, leads to decrease the wax deposit thickness with increasing the pressure drop. On another hand, increasing the inlet coolant temperature leads to decrease the shear stress and wax thickness because of decreasing the value of the crude oil viscosity (Table 3 ).

Increasing the flow rate from 2.7 to $4.8 \mathrm{~L} / \mathrm{min}$, leads to increasing the shear stress and pressure at the same inlet coolant temperature

\begin{tabular}{|c|c|c|c|c|}
\hline $\begin{array}{l}\text { Type of } \\
\text { Flow }\end{array}$ & $\begin{array}{c}\text { Temperature } \\
\left({ }^{\circ} \mathrm{C}\right)\end{array}$ & $\begin{array}{l}\text { Pressure } \\
\text { Drop }(\mathrm{Pa})\end{array}$ & $\begin{array}{c}\text { Shear Stress (using } \\
\text { the new model) }(\mathrm{Pa}) \text { at } \\
2.7 \mathrm{~L} / \mathrm{min} .\end{array}$ & $\begin{array}{c}\text { Wax } \\
\text { Thickness } \\
(\mathrm{mm})\end{array}$ \\
\hline Not Spiral & \multirow{2}{*}{14} & 1200 & 2.7 & 1.82 \\
\hline Spiral & & 4000 & 6.75 & 1.03 \\
\hline Not Spiral & \multirow{2}{*}{24} & 1000 & 2.25 & 1.5 \\
\hline Spiral & & 3400 & 5.74 & 0.85 \\
\hline Not Spiral & \multirow{2}{*}{33} & 900 & 2.03 & 0.7 \\
\hline Spiral & & 2500 & 4.22 & 0.36 \\
\hline Not Spiral & \multirow{2}{*}{40} & 600 & 1.35 & 0 \\
\hline Spiral & & 1700 & 2.87 & 0 \\
\hline
\end{tabular}
because of reducing the cross-sectional area of the pipe that affects to increase the crude oil velocity. This high velocity minimises the wax deposit on the pipe wall because of converting the laminar or turbulent flow to the spiral flow (angular flow). The high temperatures of the pipe wall lead to low shear rates and low wax thickness because of increasing the solubility of wax in the crude oil that works to reduce the crude oil viscosity (Table 4).

If we assumed, that the flow rate increased to $6 \mathrm{~L} / \mathrm{min}$ and by following the same procedure above it can be estimate the shear stress produced at different inlet coolant temperature and with and without spiral flow as shown in Table 5.

Figure 4 shows the effect of increasing the shear stress on wax deposit thickness, where at the same flow rate $2.7 \mathrm{~L} / \mathrm{min}$ it can be seen that increasing the shear stress leads to reduce wax deposit thickness from 1.8 to $1 \mathrm{~mm}$ at inlet coolant temperature $14^{\circ} \mathrm{C}$. Increasing the flow

Table 3: Estimated shear stress and wax thickness at different pressure drops and different inlet coolant temperature at flow rate $2.7 \mathrm{~L} / \mathrm{min}$ with and without the spiral flow. 
Citation: Theyab MA (2018) The Effect of Shear Stress on Wax Deposit Thickness with and without Spiral Flow. J Pet Environ Biotechnol 9: 358. doi: 10.4172/2157-7463.1000358

Page 4 of 4

\begin{tabular}{|c|c|c|c|c|}
\hline $\begin{array}{l}\text { Type of } \\
\text { Flow }\end{array}$ & $\begin{array}{c}\text { Temperature } \\
\left({ }^{\circ} \mathrm{C}\right)\end{array}$ & $\begin{array}{c}\text { Pressure Drop } \\
(\mathrm{Pa})\end{array}$ & $\begin{array}{c}\text { Shear Stress (using } \\
\text { the new model) }(\mathrm{Pa}) \\
\text { at } 4.8 \mathrm{~L} / \mathrm{min} .\end{array}$ & $\begin{array}{c}\text { Wax } \\
\text { Thickness } \\
(\mathbf{m m})\end{array}$ \\
\hline Not Spiral & \multirow{2}{*}{14} & 3000 & 6.75 & 1.5 \\
\hline Spiral & & 8000 & 13.51 & 0.78 \\
\hline Not Spiral & \multirow{2}{*}{24} & 2700 & 6.08 & 1.36 \\
\hline Spiral & & 7000 & 11.82 & 0.61 \\
\hline Not Spiral & \multirow{2}{*}{33} & 2100 & 4.73 & 0.63 \\
\hline Spiral & & 6100 & 10.3 & 0.39 \\
\hline Not Spiral & \multirow{2}{*}{40} & 1200 & 2.7 & 0 \\
\hline Spiral & & 4500 & 7.6 & 0 \\
\hline
\end{tabular}

Table 4: Estimated shear stress and wax thickness at different pressure drops and different inlet coolant temperature at flow rate $4.8 \mathrm{~L} / \mathrm{min}$ with and without the spiral flow.

\begin{tabular}{|c|c|c|c|c|}
\hline $\begin{array}{l}\text { Type of } \\
\text { Flow }\end{array}$ & $\begin{array}{c}\text { Temperature } \\
\left({ }^{\circ} \mathrm{C}\right)\end{array}$ & $\begin{array}{l}\text { Pressure } \\
\text { Drop }(\mathrm{Pa})\end{array}$ & $\begin{array}{c}\text { Shear Stress (using } \\
\text { the new model) }(\mathrm{Pa}) \text { at } \\
6 \mathrm{~L} / \mathrm{min} .\end{array}$ & $\begin{array}{c}\text { Wax } \\
\text { Thickness } \\
(\mathbf{m m})\end{array}$ \\
\hline Not Spiral & \multirow{2}{*}{14} & 4000 & 9 & 1 \\
\hline Spiral & & 10000 & 16.15 & 0.6 \\
\hline Not Spiral & \multirow{2}{*}{24} & 3000 & 6.75 & 0.8 \\
\hline Spiral & & 8000 & 12.92 & 0.5 \\
\hline Not Spiral & \multirow{2}{*}{33} & 2500 & 5.63 & 0.4 \\
\hline Spiral & & 7000 & 11.3 & 0.3 \\
\hline Not Spiral & \multirow{2}{*}{40} & 1500 & 3.38 & 0 \\
\hline Spiral & & 5000 & 8.1 & 0 \\
\hline
\end{tabular}

Table 5: Estimated shear stress and wax thickness at different pressure drops and different inlet coolant temperature at flow rate $6 \mathrm{~L} / \mathrm{min}$ with and without the spiral flow.

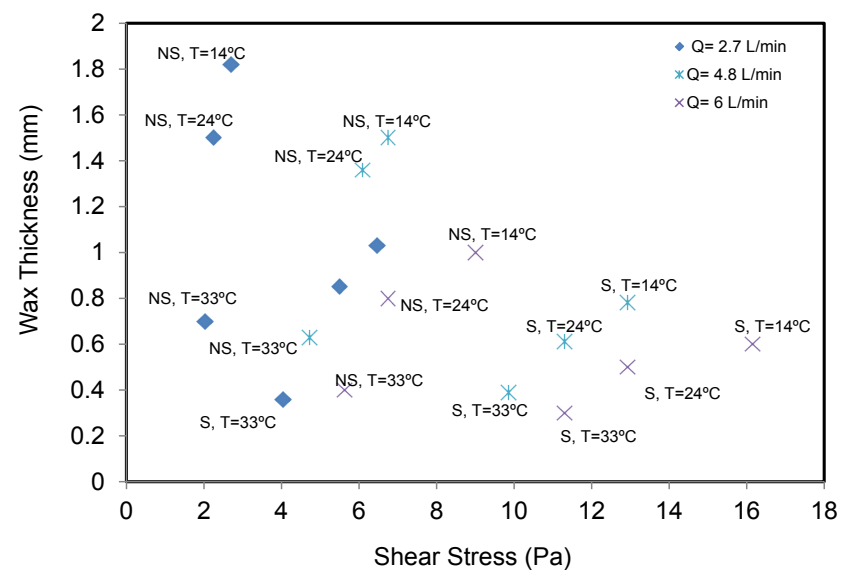

Figure 4: The effect of shear stress with spiral flow (S) and non-spiral flow (NS) on wax deposit thickness at different pressures and different inlet coolant temperatures.

rate to $4.8 \mathrm{~L} / \mathrm{min}$ leads to increase the shear stress that works to reduce wax deposit thickness from 1.5 to $0.78 \mathrm{~mm}$ at the same temperature. While increasing the flow rate to $6 \mathrm{~L} / \mathrm{min}$ results in increasing the shear stress that reduced the wax thickness from 1 to $0.6 \mathrm{~mm}$.

\section{Conclusion}

The current work studied the effect of the shear stress on wax deposition inside the hydrocarbon pipeline. A series of experimental data of Theyab and Diaz [5,6] was used to estimate the shear stress value resulting from the pipe wall surface and the twisted plate that was inserted into the pipe to create spiral flow. This work presented a new correlation (model) to calculate the shear stress depending on the concept of, the forces that influence on the crude oil flow in the pipe with and without inserting the twisted plate depending on the pressure drop along the pipe. It was observed that the wax deposit thickness decreased with increasing the shear stress while the shear stress decreased, in case of crude oil flow without spiral flow leading to increasing the wax deposit thickness. However, an increase in flow rates results in a decrease in the wax deposition because of increasing the shear stress. Also, it was observed that increasing the inlet coolant temperature leads to decrease the shear stress and wax thickness because of increasing the solubility of the wax molecules in the bulk of the crude oil that leading to decreasing the value of the crude oil viscosity. This study presented the newly developed model as a base model for similar studies to calculate the shear stress in the fluid flow pipelines using the twisted plate to create spiral flow.

\section{References}

1. Bern PA, Withers VR, Cairns RJR (1980) Wax deposition in crude oil pipelines Presented at the European Offshore Petroleum Conference and Exhibition London, England.

2. Leontaritis KJ, Geroulis E (2011) Wax deposition correlation-application in multiphase wax deposition models. Presented at Offshore Technology Conference, Houston, Texas, USA.

3. Dwivedi P (2010) An investigation of single-phase wax deposition characteristics of South Pelto Oil under turbulent flow. MS Thesis, the University of Tulsa, Tulsa, Oklahoma.

4. Venkatesan $R$, Singh $P$, Fogler HS (2002) Delineating the pour point and gelation temperature of waxy crude oils. SPE Journal 7: 349-352. SPE-72237-PA.

5. Theyab MA, Diaz P (2016a) Experimental study of wax deposition in pipeline Effect of inhibitor and spiral flow. International Journal of Smart Grid and Clean Energy 5: 174-181.

6. Theyab MA, Diaz P (2016b) Experimental study on the effect of spiral flow on wax deposition thickness, One petro, presented at SPE Russian Petroleum Technology Conference and Exhibition, Moscow, Russia, 24-26. SPE 181954-MS.

7. Crawford RJ (2005) Plastics Engineering (3rd edn). Elsevier ButterworthHeinemann, Burlington, UK.

8. Gebrehiwot SZ (2014) Manufacturing and rheological analysis of spiral flow test piece. Degree Thesis, Plastics Technology, Arcada University of Applied Sciences, Helsinki, Finland. 